\title{
MASTER ERROR ELIMINATION IN FORCED GEAR ENGAGEMENT TESTING MACHINE USING HARMONIC ANALYSIS THROUGH FAST FOURIER TRANSFORM
}

\author{
Dănuț-Iulian Stanciu ${ }^{1}$, Gheorghe Ion Gheorghe2, Doina-Daniela Cioboată ${ }^{1}$ \\ ${ }^{1}$ National Institute of Research and Development for Mechatronics and Measurement Technique - INCDMTM, \\ Bucharest, Romania \\ ${ }^{2}$ VALAHIA University from Târgoviste, Romania \\ Email: danut.stanciu@incdmtm.ro, gheorghe.gheorghe1946@valahia.ro, cioboatadoina@yahoo.com
}

\begin{abstract}
The growth in the capacity of production of gears and the higher industrial gear quality requirements call for the use of fast and accurate methods of checking gears right in the manufacturing flows. This paper presents a method of rapid and accurate verification of gears by applying the Fourier Transform analysis method to the variation of the distance between the shafts of two gears meshed together in a forced engagement. The paper also presents a method of replacing standard gears - used on test units featuring a tooth fitted between the standard gear and the measuring gear - with a regular gear, while maintaining the same level of accuracy of the measurement.
\end{abstract}

Keywords: Master Error Elimination, Forced Gear Engagement, Testing Machine, Harmonical Analysis, Fourier Transform, Novel Method for Gear Checking.

\section{Introduction}

Gears are some of the most important elements in car construction, a high amount being used in all of its branches, especially in the automotive industry.
According to statistics (for example, according to the website www.statista.com), the global toothed gear market consisted in 25.91 billion US dollars in 2018, and it is estimated to grow to as high as 31.9 billion US dollars in 2023 (Figure 1).

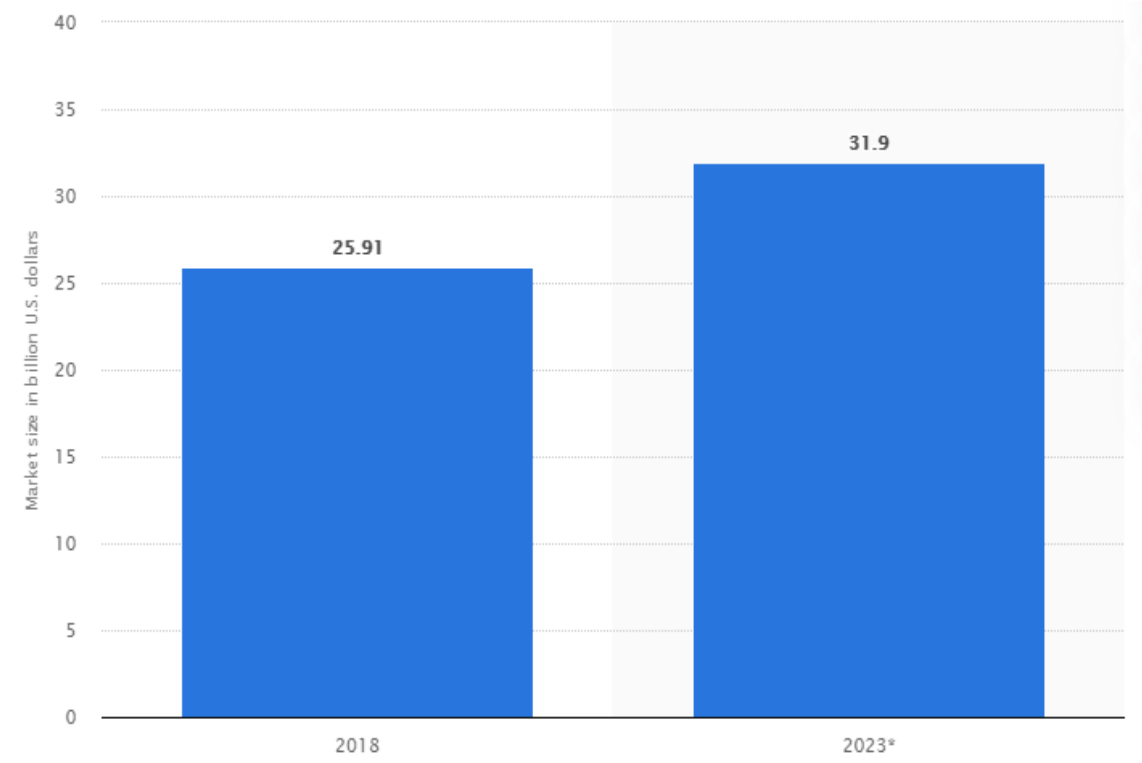

Figure 1: Toothed gear production value, reached in 2018 and estimated for 2023 [12]

Therefore, dimensional verification is essential to achieve high transfer efficiencies in conjunction with a low operating noise. 


\section{Presentation of the Method}

A complex and fast widely used method of testing a gear is that of a forced tooth engagement or both sides (flanks) - which is generally used for the validation of an engagement by assessing the level of noise and vibration produced.

The kinematic diagram of checking a gear by the method of forced tooth engagement fitted between the standard gear and the measuring gear is shown in Figure 2.

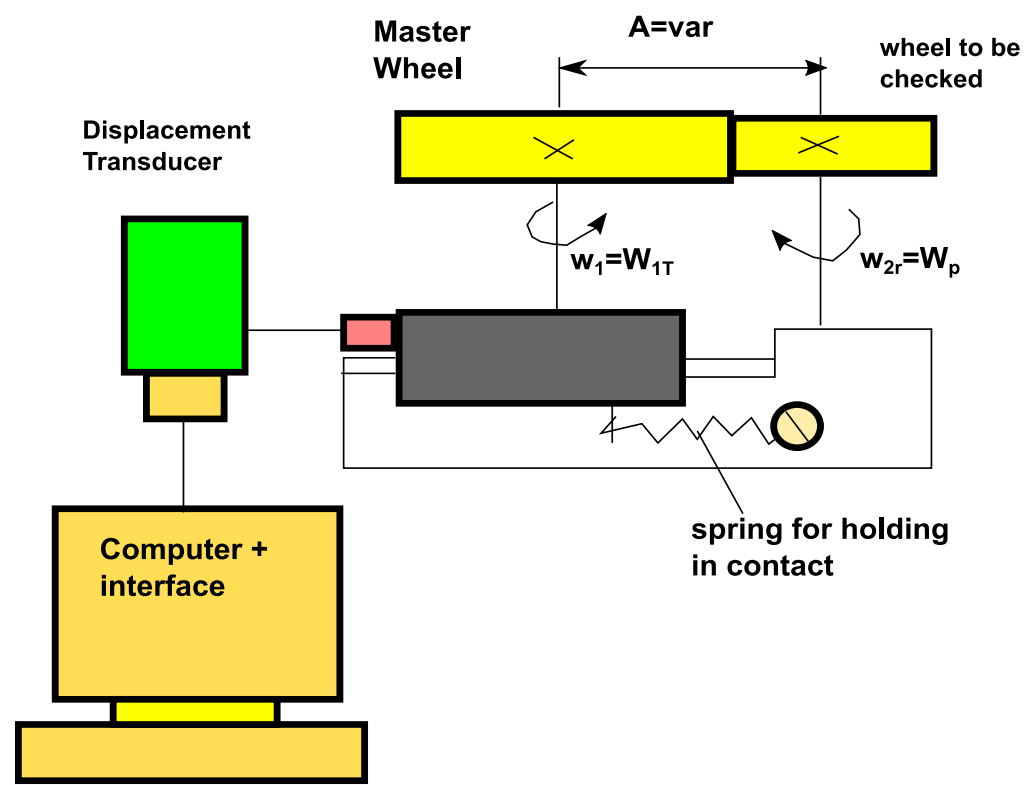

Figure 2: The general kinematic diagram of checking a gear by the method of forced tooth engagement

Description: The standard gear (1) is involved in a forced engagement to make contact with the measuring gear (2) via the spring (3). A linear motion generated by the geometric deviations of the two gears in the engagement is obtained by rotating the measuring gear (1) with the help of a moving table reducer (6) (that is an integral part of the standard gear (1)).
The displacement of the moving table is captured by the displacement transducer (4) and stored in the computer (5).

In Figure 3, there is a representation of the variation of the distance between the shafts for a gear involved in an engagement based on a tooth fitted between the standard gear and the measuring gear.

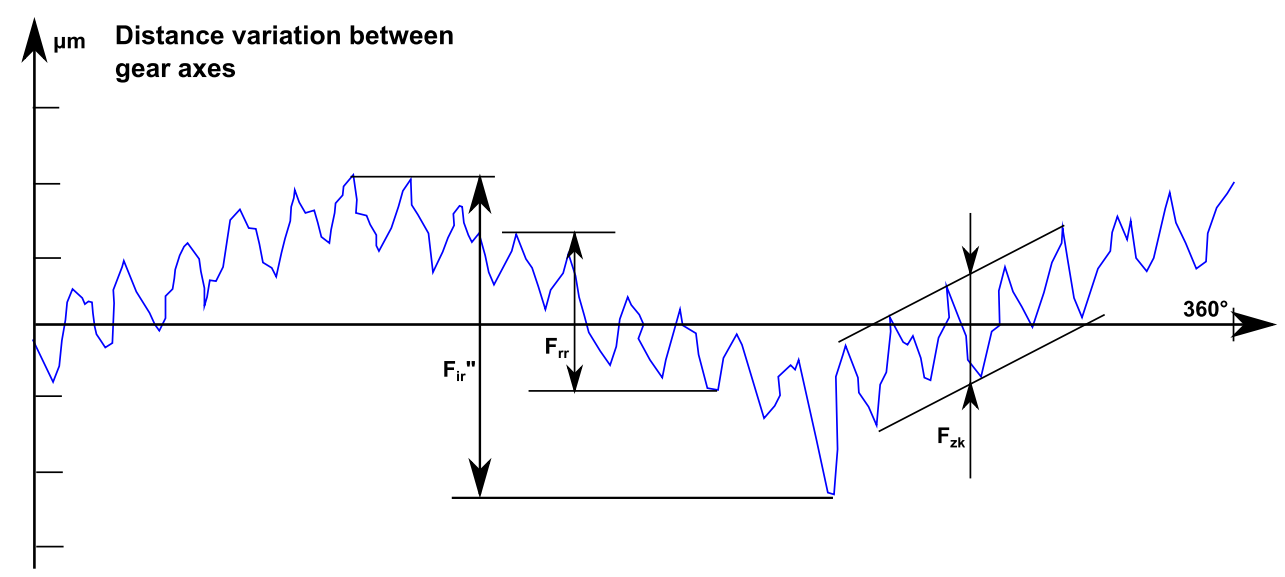

Figure 3: The variation of the distance for a forced tooth engagement

Figure 3 features the following elements:

- $F^{\prime \prime}$ ir i.e. the total variation of the measuring distance between the shafts (the radial composite error)

- $F_{z k r}$ i.e. the maximum amplitude of the high frequency component
- Frr. i.e. the radial variation tooth-tooth As one can see in Figure 3, the variation of the distance between the shafts of the two gears placed in a forced engagement has a compound periodic shape which leads to the idea of using a harmonic analysis (the Fourier Transform) to check the 
connection between the geometric parameters of the gear and the amplitudes of the harmonic components resulting from the from harmonic analysis.

The Fourier Transform stipulates that any continuous periodic function can be approximated by a sum of perfect sinusoids. The re-composition of a continuous periodic curve - previously decomposed using the Fourier Transform - is performed with the help of the Reverse Fourier Transform.

In this context, the Fourier Transform is:

$$
F(s) \equiv \int_{-\infty}^{\infty} f(x) e^{-2 \pi i s x} d x
$$

and the Reverse Fourier Transform is given by the following formula:

$$
f(x) \equiv \int_{-\infty}^{\infty} F(s) e^{2 \pi i s x} d s
$$

in which:

$f(x)$ stands the function to which the transform is applied

$F(s)$ is the Fourier Transform

$i$ stands for the sinusoidal order obtained $(\mathrm{i}=0 \ldots \infty)$

These formulas are applicable to continuous periodic functions with a known mathematical formula. In case of processes associated with an unknown mathematical formula, but whose data used for processing - have a periodic component (such as data collected in measurement processes), or for discrete processes, the Fourier Transform formula for discrete processes applies, as shown in the following lines.

The Fourier Transform formula for discrete processes is given by the following formula:

$$
X_{k}=\sum_{j=0}^{N-1} x_{j} e^{-2 \pi i j K / N}
$$

and the Reverse Fourier Transform for discrete processes is given by the following formula:

$$
x_{j}=\frac{1}{N} \sum_{k=0}^{N-1} X_{k} e^{2 \pi i j k / N}
$$

in which:

$x$ stands for the values obtained after the measurement, while

$X$ stands for the values of the discrete Fourier Transform (that have a complex form).
After processing a set of discrete samples of $\mathrm{N}$ points, N/2 real components and N/2 imaginary components are obtained, which will generate a frequency spectrum from 0 to $\mathrm{N} / 2$.

In general, the Fourier transform is applied mainly to electrical / electromagnetic phenomena associated with the concept of frequency (phenomena whose development takes place over time). In order to be able to apply the Fourier Transform to the measurements performed on the mechanical components (phenomena whose development takes place in space), it is necessary to make a coordinate transformation from the time domain to the space domain. Consequently, the unit of time is declared as a rotation - in case of rotating mechanical components - or as an arbitrary length in case of linear mechanical components. In this paper, in which we discuss revolving mechanical components, we shall use the transformation from 1 rotation to 1 second and we shall continue to use the term 'frequency' which in our case stands for the number of events (sinusoids) per rotation.

As an example of the application of the Fourier Transform to the processing of data collected when measuring a revolving part, a simulation is performed on a rotating part of the shape shown in Figure 4 (shape deviations are exaggerated on purpose, in order to support the main idea of the paper).

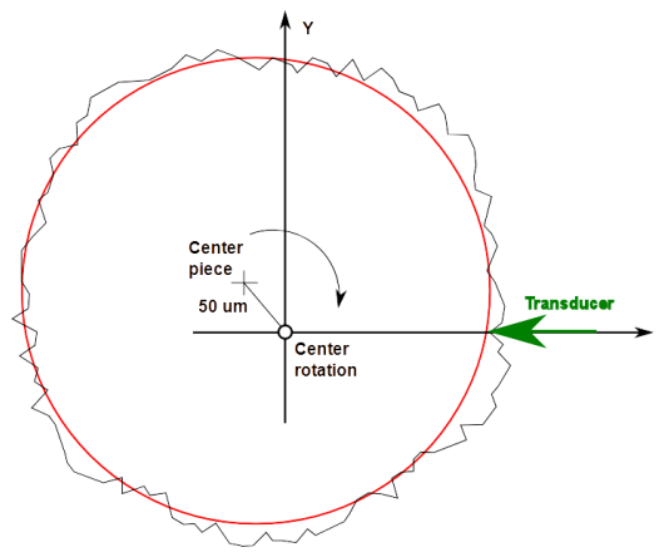

Figure 4: A revolving part featuring simulated shape deviations is rotated eccentrically

By generating the linear representation of the values collected by the Transducer in Figure 4, a curve is obtained. This curve contains the shape deviations of the part in conjunction with the eccentricity given by the eccentric rotation of the part, as shown in Figure 5. 


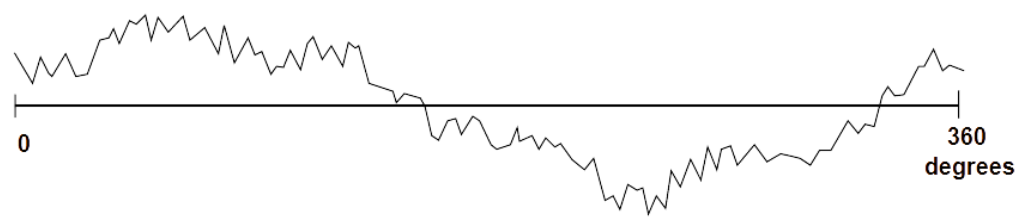

Figure 5: The variation of the values collected by the horizontal transducer

Via the Fourier Transform (which, as we have shown above, decomposes any continuous function into a sum of perfect sinusoids), some of the components can be eliminated or preserved, thus performing different kinds of filtering. For example, by keeping the first order component, which stands for a single sinusoid, we can detect the eccentricity of the part represented in Figure 4.
By processing, with the Fourier Transform, the data represented in Figure 5 and by keeping the first order component, we obtain the eccentricity variation curve (Figure 6) - on which it is observed that the maximum variation on the $\mathrm{Y}$ axis is of $99,964 \mu \mathrm{m}$, which is close to the value of $2 \times 50 \mu \mathrm{m}$ introduced in the simulation.

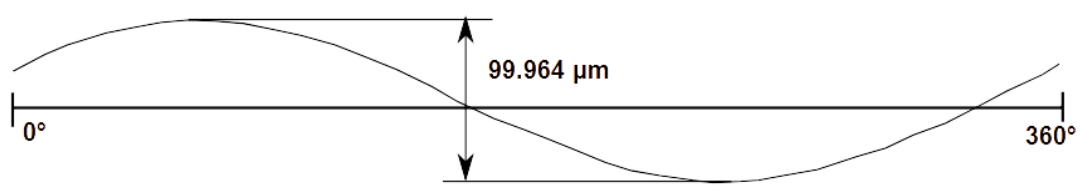

Figure 6: The graphical representation of the restored curve measured by preserving the first order component exclusively

In order to perform an analysis based on surface deviations - without being influenced by the introduced eccentricity - the Fourier Transform applied to the points collected by the transducer is used, the 0 order component (eccentricity) is eliminated, and the curve is recomposed by applying the inverse Fourier Transform. A curve simi-lar to that in figure 7 is obtained.

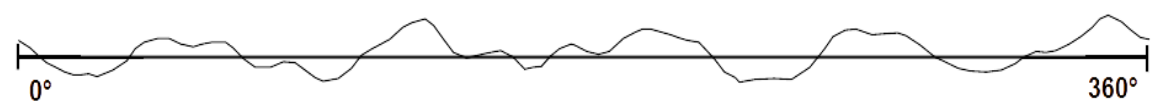

Figure 7: The variation of the curve picked up by the transducer, after removing component 0 (eccentricity)

These experiments show that there is a direct connection between the different shape deviations of a revolving piece and the elements of the Fourier Transform, a connection that will be further analysed in the paper.

\section{Engagement Simulation}

From the presentation of the manner in which the Fourier Transform works, and from the variation of the distance between the shafts of the two gears placed in a forced engagement it is possible to determine the influence of various geometric errors of the gears by analysing the sinusoidal components of the variation curve that were obtained using the Fourier Transform. In order to be able to find the unequivocal link between a geometric deviation and the associated frequency or set of frequencies, it is necessary to mesh together a standard gear and several gears with known geometric deviations, to memorize the variation of the distance between the shafts of the gears, to apply the Fourier Transform to the variation of the distance between the shafts of the two gears, and to determine the frequencies that are associated with the geometric deviation of the gear that needs to be tested.

This approach requires the use of the following elements:

1 - a standard gear, with the modulus equal to that of the gear that needs to be checked 2 - performing complex geometric measurements for each of the gears used in the test. 3 - performing an effective measurement on a test unit featuring a tooth fitted between the standard gear and the measuring gear.

The disadvantages of this approach are the fact that the standard gears are expensive and hard to obtain and the geometric measurements performed with classical measuring equipment are accurate but slow; to these drawbacks also adds up the fact that a simulation based on a real unit will cause errors generated by the test unit itself. To eliminate these shortcomings, a numerical simulation of the forced tooth engagement was developed. Different errors 
were introduced in the flanks of the tooth gears. Taking into account the aspects presented above, and, in order to apply a unique pattern to all gear simulations, the simulation of the tooth flanks was chosen by linear interpolation.

In order to achieve the linear interpolation, the Cartesian coordinates of the points on the flanks of the teeth are first obtained as in Figure 8.

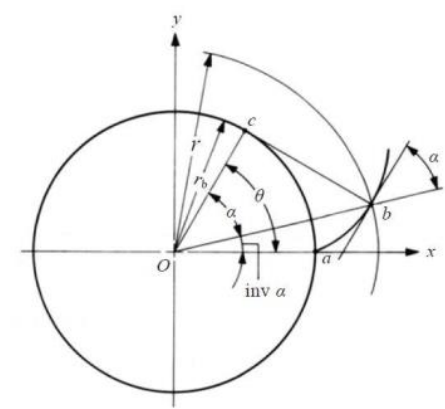

Figure 8: Geometric description of tooth flanks

As per Fig 8. for a point placed at an angle $\alpha$, we have the following:

$$
\begin{aligned}
& \alpha=\arccos \left(\frac{r_{b}}{r}\right) \\
& x=r \cos (\alpha) \\
& y=r \sin (\alpha)
\end{aligned}
$$

in which:

$r_{b}$ stands for the radius of the base circle

$r$ stands for the current radius ranging from the radius of the bottom circle to the radius of the outer circle.
From the Cartesian coordinates of the tooth flanks, the linear interpolation of the tooth flank is then obtained; from the flank of the tooth, by operations of copying, translating and rotating, the flanks of all teeth are obtained and stored in the memory to generate a simulated gear.

The gear simulation process is an iterative process in which, by using two digitized gears, whose parameters are stored, a series of rotational and translational movements are performed (fig. 9) so that the distance between the conjugate flanks is less than a certain limit value (in our case a value of $1 \mathrm{e}^{-12} \mathrm{~m}$ was used). To perform the simulation, a specialized software was developed by the authors of the paper. The role of the software is to perform a simulation of a forced gear engagement and to obtain the variation of the distance between the shafts of the two gears and to process it via a harmonic analysis. The main screen of the application is presented in Figure 10 .

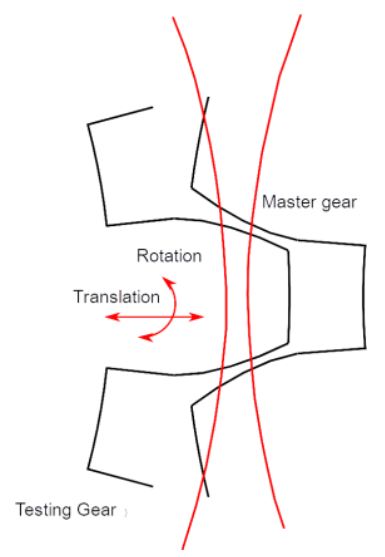

Figure 9: The mode of generating movements to perform the forced gear simulation

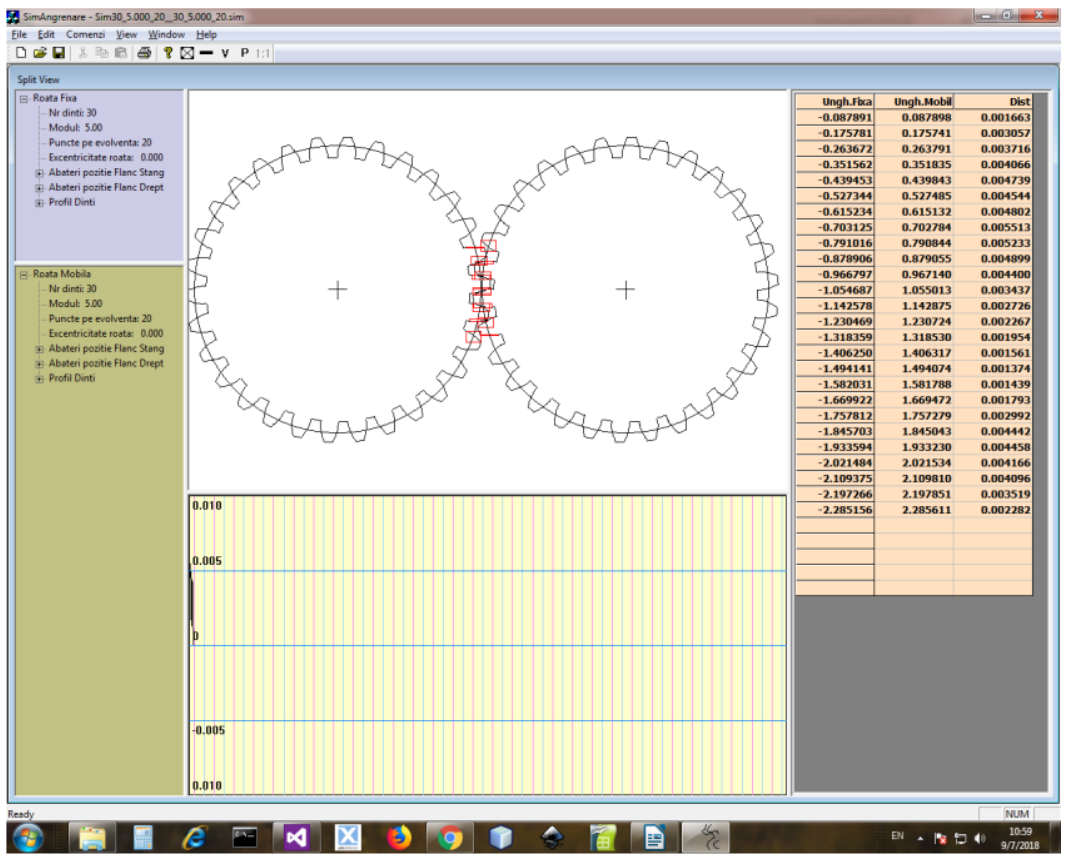

Figure 10: The main screen of the forced engagement simulation software 
Having this simulation tool at hand, the next step is to perform a simulated forced engagement between a standard (virtual) gear and a (virtual) gear to which known values of geometric deviations have been introduced.

The main challenge is to determine the correlation between the amplitudes of the Fourier Transform components and the deviations from the imposed geometric shape of the gear that needs to be checked. To this end, simple known geometric deviations were initially introduced to the gear that needs to be checked, the simulation was performed with the help of the specialized software -, and the amplitude correlation of the components resulting from the analysis made with the Fourier Transform and the entered geometric values was performed.

Thus, simulations were conducted to determine the side clearance, the eccentricity of the dividing circle with respect to the axis of rotation, the pitch deviations, the deviations from the evolventic profile of the tooth flanks, and the shocks. Following the simulations and the analyses performed, the results described below were obtained.

(1) Side flank clearance - is accurately determined by the Fourier Transform by extracting the amplitude of the order 0 component from the obtained frequency spectrum and dividing it by the experimentally determined parameter with a value of 2.798 (an experimentally determined value which is caused by the wedge effect).

(2) Eccentricity of the engagement - is determined directly from the amplitude of the first order component of the frequency spectrum obtained by the Fourier transform

(3) Deviations from the evolventic profile - is determined at the overall level of the entire gear by filtering the variation of the distance between the shafts by removing components between the order of 0 and the order given by the number of flanks of the gear that needs to be checked and by removing components larger than $3.5 *$ the number of flanks of the gear that needs to be checked, recomposing the profile and determining the difference between the maximum and the minimum values on the recomposed profile.

(4) Pitch deviation - is not accurately determined by harmonic analysis, hence it is necessary to use another method (possibly by means of an angular transducer with an accuracy appropriate to the number of teeth of the gear that needs to be checked).

(5) Shocks are small deformations at the tooth surface (and which directly influence the criterion of smooth operation) that are determined by retaining the harmonic components with a frequency higher than about 4 times the number of flanks of the gear that needs to be checked (this processing also requires a practical test in determining the harmonics that needs to be selected); by recomposing the profile with the eliminated harmonics, a profile whose maximum value will be reported in absolute value is obtained.

Next, by using these methods of determination, we shall simulate a complex engagement between a standard gear and a (simulated) gear that needs to be checked, with the view to obtain the deviations generated by the side clearance, the deviations from eccentricity and the deviations from the evolventic profile. The gear that needs to be checked will have deviations from the side clearance of $0.2 \mathrm{~mm}$, deviation from eccentricity of $0.15 \mathrm{~mm}$ and deviation from the maximum evolventic profile of $0.027 \mathrm{~mm}$ (the deviation from the evolventic profile was randomly generated and the maximum value was stored).

After performing the simulation, we shall obtain a variation of the distance between the shafts of the two gears meshed up in a simulated forced gear engagement shown in Figure 11.

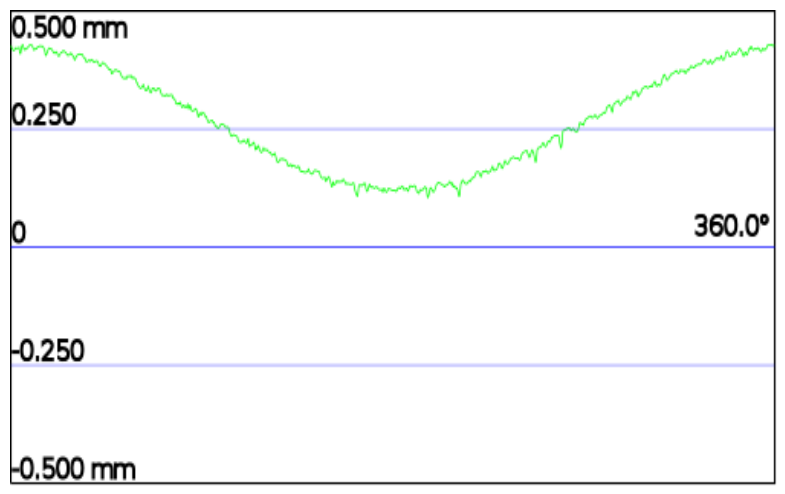

Figure 11: The diagram of the variation of the distance between the shafts for combined deviations of side clearance $(0.2 \mathrm{~mm})$, eccentricity $(0.15 \mathrm{~mm})$ and deviation of flank profile (maximum $0.027 \mathrm{~mm}$ )

Next, the processing spectrum is presented in Figure 12.

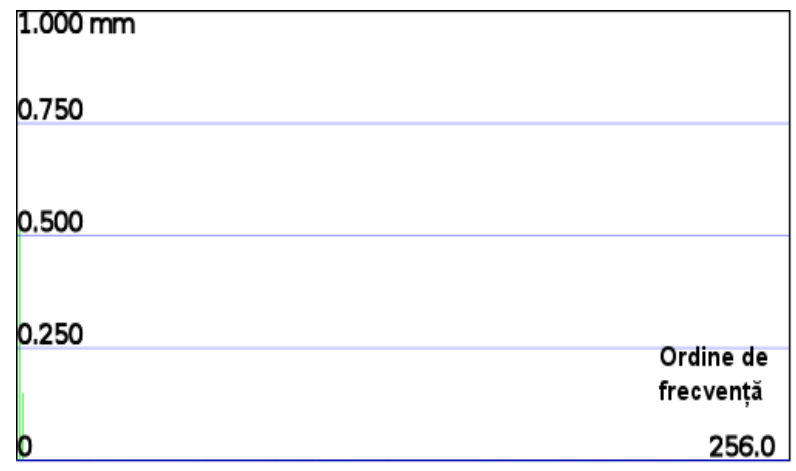

Figure 12: The harmonic processing spectrum for an engagement featuring combined deviations of side clearance $(0.2 \mathrm{~mm})$, eccentricity $(0.1 \mathrm{~mm})$ and flank profile $(0.027 \mathrm{~mm})$ 
The numerical values of the components of order 0 and 1 (which will give us the values of the side clearance and the eccentricity) are presented in Table 1.

\begin{tabular}{|l|l|}
\multicolumn{2}{c}{ Table 1 } \\
\hline Order & Amplitude $(\mathrm{mm})$ \\
\hline 0 & 0.5408 \\
\hline 1 & 0.1503 \\
\hline
\end{tabular}

From this table, we will obtain the value of the side clearance by dividing the value of the amplitude of the component of order 0 by 2.789 (presented above), resulting in a value of $0.1932 \mathrm{~mm}$; in order to detect the eccentricity value, the value of the amplitude of order 1 (representing the eccentricity) was retained, resulting in a value of $0.1503 \mathrm{~mm}$.

In order to obtain the deviation from the flank profile of the teeth, a filter was introduced in which components 0 and 60 and those greater than 200 are eliminated (according to the previous indications), and following the filtering, the following diagram of the variation of the distance between the shafts was obtained (fig. 13).

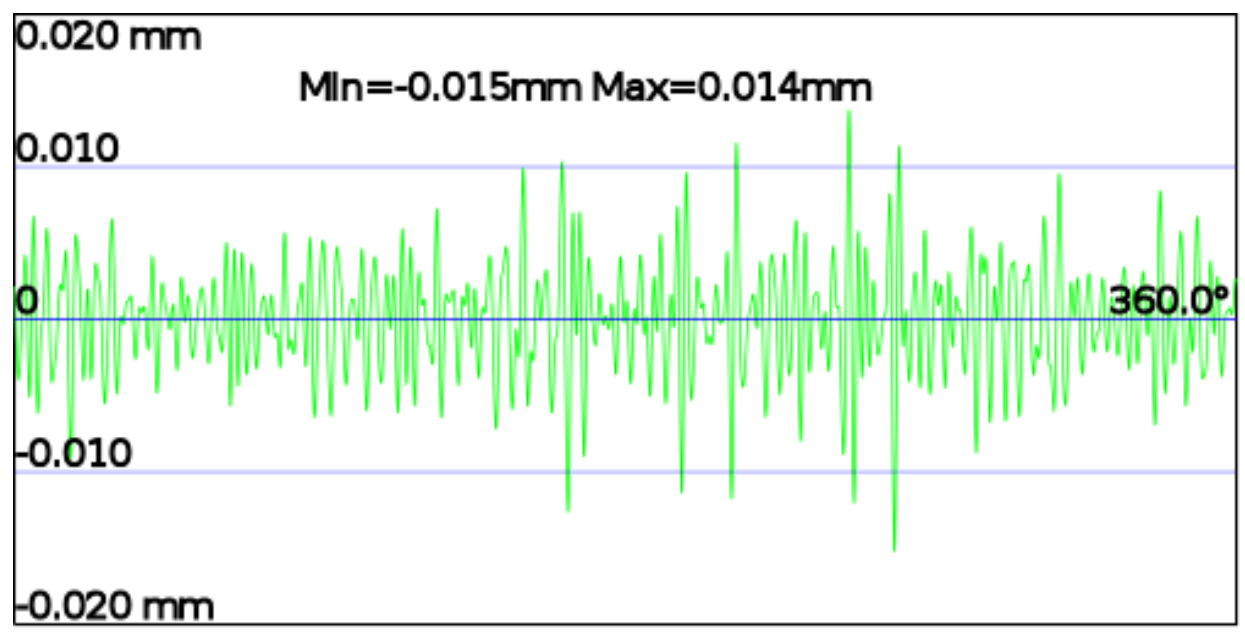

Figure 13: The diagram of the variation of the distance between the shafts for components between 0 - 60 and higher than 200

The comparative results between the geometric deviations introduced and the geometric deviations obtained are presented in Table 2.

Table 2

\begin{tabular}{|l|l|l|l|}
\hline & $\begin{array}{l}\text { Input data } \\
(\mathrm{mm})\end{array}$ & $\begin{array}{l}\text { Data obtained by processing } \\
(\mathrm{mm})\end{array}$ & $\begin{array}{l}\text { Resulting deviation } \\
(\mathrm{mm})\end{array}$ \\
\hline Side clearance & 0.2000 & 0.1932 & 0.0068 \\
\hline Eccentricity & 0.1500 & 0.1503 & 0.0003 \\
\hline $\begin{array}{l}\text { Deviation from the } \\
\text { evolventic profile }\end{array}$ & 0.0270 & 0.0290 & 0.0020 \\
\hline
\end{tabular}

The deviation analysis has shown that the method gave good results and that it can be used successfully to determine the deviations of the geometric elements of the gears with evolventic teeth.

All of these simulations were performed using a teeth engagement consisting of a standard gear (which is geometrically perfect) and a gear that needs to be checked. In practice, standard gears are expensive and hard to acquire, so the forced gear engagement test is performed between a certain gear, used as a standard one, and the gear that needs to be checked. By using the linearity of the Fourier Transform, the deviations of the standard gear can be eliminated, so that the test result will be very close to an ideal test made with a physical standard gear. To achieve this, the simulation software must be used according to the steps described below.

I. Generating the reference spectrum of the gear that is designated to be used as a standard gear.

I.1 Measuring the gear that needs to be checked by collecting points in Cartesian coordinates on each side of the teeth of the gear (it is recommended to collect as many points as possible on each side).

I.2 Running the simulation software and generating a gear engagement consisting of the perfect mobile gear and the fixed standard gear in which the perfect theoretical flanks of the teeth will be replaced with the flanks obtained via the coordinate measuring machine. 
I.3 Performing the simulation.

I.4 Applying a Fourier Transform to the variation of the distance between the shafts.

I.5 Storing the values of the Fourier Transform parameters in a file.

I.6 Completing the processing.

II. Performing the measurement by using a usual gear as a standard gear.

II.1. Mounting the gear in the measuring unit.

II.2 Performing the measurement.

II.3 Applying a Fourier Transform to the variation of the distance between the shafts

II.4 Loading the values of the results of applying the Fourier transform from the file saved, as specified at 1.5 .
II.5 Based on the linearity property of the Fourier Transform, a complex difference is made between the current spectrum of the measurement and the spectrum saved in the file (of the gear used as a standard); thus, are removed the influences of the side clearance and the eccentricity of the standard gear.

II.6. Recomposing the distance between the two gears by applying the Reverse Fourier Transform

II.7 Carrying out the necessary processing in order to obtain the parameters of the forced engagement by using the methods presented above.

This processing is shown schematically in figure 14.

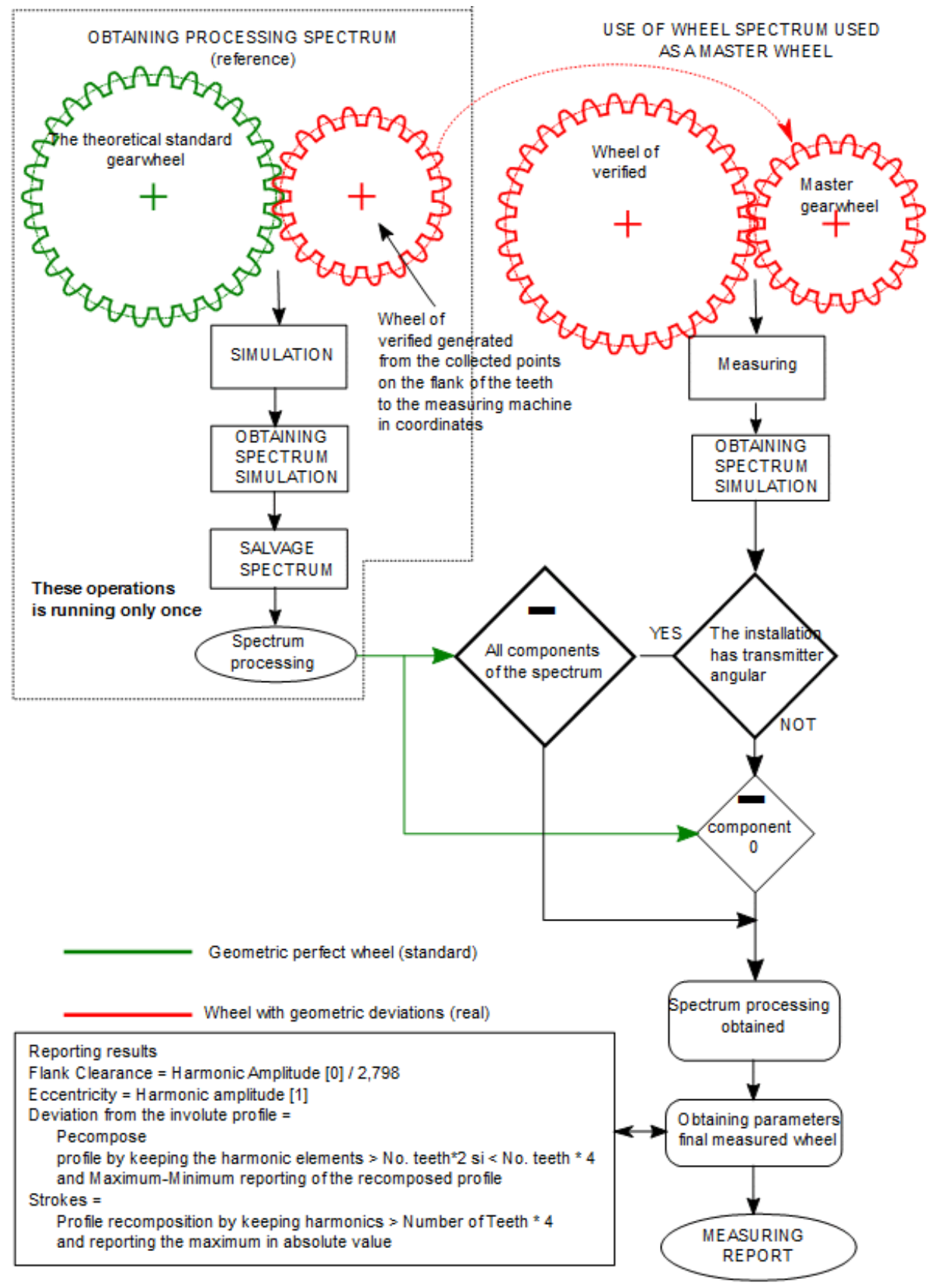

Figure 14: Complex processing for removing standard gear deviations 
The verification of the processing method, shown schematically in Figure 14, is applied to a simulated engagement between two gears, each of them having geometric deviations as follows:

- the standard gear - the value of the maximum deviation from the evolventic profile is of $0.011 \mathrm{~mm}$; the eccentricity value is of $0.2 \mathrm{~mm}$; and the flank clearance is of $0.2 \mathrm{~mm}$

- the gear that needs to be checked - the value of the maximum deviation from the evolventic
- profile is of $0.006 \mathrm{~mm}$; the value of the introduced side clearance is of $0.1 \mathrm{~mm}$; and the eccentricity is $0.1 \mathrm{~mm}$.

After simulating and storing the spectrum of the standard gear and then performing the simulation between the two gears with geometric deviations, extracting the spectrum of the standard gear, and applying the processing methods shown above, the following deviations of the gear that needs to be checked result (Table 3).

Table 3

\begin{tabular}{|l|l|l|l|}
\hline & $\begin{array}{l}\text { Introduced value } \\
(\mathrm{mm})\end{array}$ & $\begin{array}{l}\text { Measured (simulated value) } \\
(\mathrm{mm})\end{array}$ & $\begin{array}{l}\text { Deviation } \\
(\mathrm{mm})\end{array}$ \\
\hline Eccentricity & 0.100 & 0.100 & 0.000 \\
\hline Side clearance & 0.100 & 0.100 & 0.000 \\
\hline Deviation of the tooth flank profile & 0.006 & 0.009 & 0.003 \\
\hline
\end{tabular}

In practice, to obtain the standard gear spectrum of a real gear, we scan and digitize the flanks of the teeth, we enter the values in the simulation software (which will approximate each flank to an involute by applying the lower squares method), we perform the simulation and then store the standard gear spectrum. The spectrum of the standard gear, determined this way, will then be used for further processing on test units featuring a tooth fitted between the standard gear and the measuring gear, by applying the method of determination based on a forced engagement-based method.
At the DACIA-RENAULT automotive factories in Mioveni were designed a series of units used for testing the pinions of the gearboxes before being finally mounted on the end product.

The processing performed on these units was based on some of the processing methods presented above. Figure 15 shows one of these units, a unit that verifies the shocks, the eccentricity and thickness of the phosphate layers of the pinions of gears II, III, IV, V.

This unit is currently part of the gearbox assembly lines of DACIA-RENAULT.

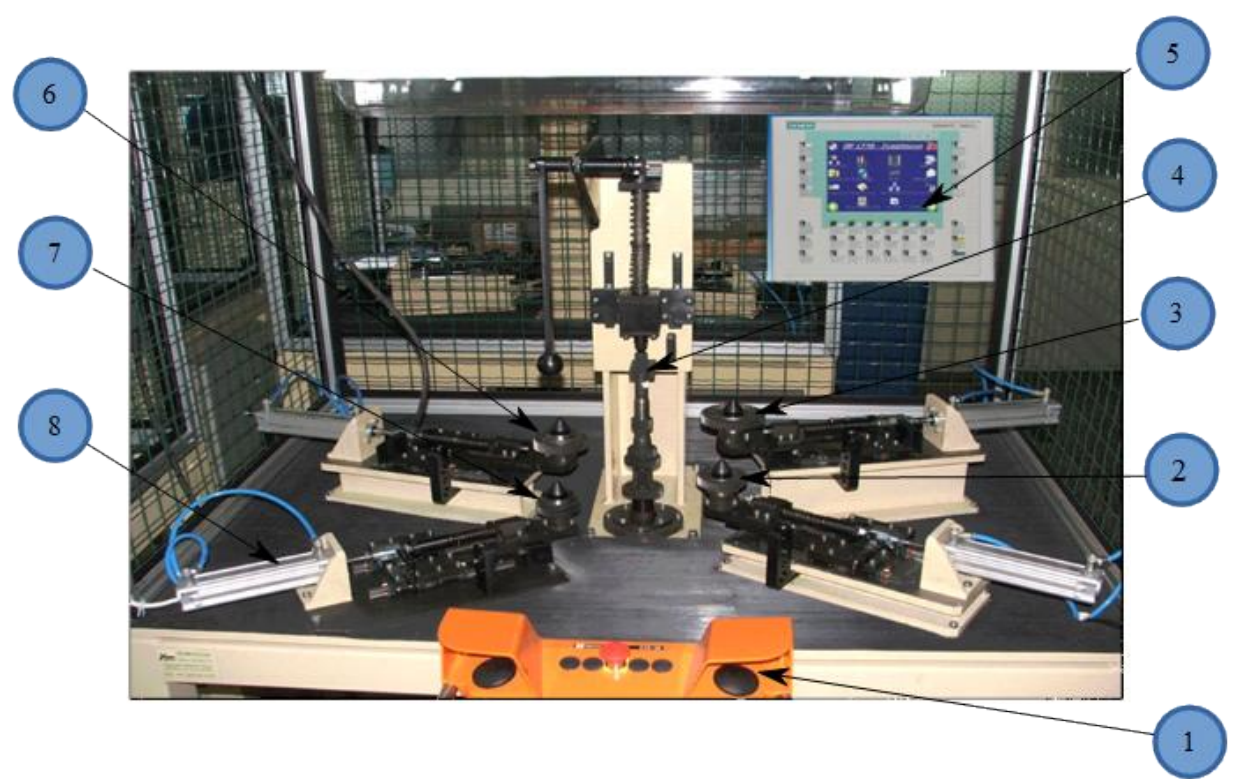

Figure 14: A unit used for checking gears II-V, determining side clearance (phosphate layer thickness), eccentricity

Legend:

1 - Bi-manual control desk

2 - Gear III pinion

3 - Gear I pinion

4 - Drive shaft

5 - Industrial computer
6 - Gear II pinion

7 - Gear IV pinion

8 - Pneumatic cylinder used for

maintaining the engagement 


\section{Further Work}

The use of the harmonic analysis method gave very good results in the performed simulations, as well as in practical experiments.

The main advantage of this method is the high speed of obtaining the main parameters of the gears (which allows its integration into the manufacturing flow) combined with a sufficiently good accuracy for a unit operating on the production line.

In order to improve the results mentioned, it is necessary to carry out a much larger number of practical experiments, possibly to create an Artificial Intelligence module that re-adjusts the connection between the components of the Fourier Transform spectrum and the geometric deviations of the gears.

\section{Conclusions}

The method proposed by the authors of the paper hereby is a new approach to rapid and accurate verification of gears. It is based on the idea of applying the Fourier Transform analysis method to the variation of the distance between the shafts of two gears meshed together in a forced engagement. It can save precious time and money, while ensuring a satisfactory level of accuracy, making it the right choice for inclusion in a plant production line.

The proprietary software developed by the authors was aimed at performing a computer-based simulation tailored to the said approach and it has turned out quite effective.

\section{References}

[1] Nicolae Sîrbu, "Cercetări privind solicitările din carcasa cutiei de viteze sumatoare în vederea reducerii zgomotului și îmbunătățirea soluției constructive", 'Transilvania' University of Brașov, Doctoral thesis abstract, 2014;
[2] Banică, M., "Optimizarea dinamicii angrenajelor", Risoprint Publishing House, Cluj-Napoca, 2006;

[3] "Prosig Noise and Vibration Measurement Handbook, Sixt Edition" - Handbook, www.prosig.com

[4] Anders Brandt, "Noise and Vibration Analysis: Signal Analysis and Experimental Procedures", 2011, ISBN:9780470978160;

[5] Gheorghe Ion Gheorghe, Valentina Băjenaru, Iulian Ilie, "Ingineria Mecatronică și CyberMixMecatronică pentru Construcția Intreprinderii Digitale şi Industriei Inteligente (4.0)" - 2019,, ISBN 978-606-8261-29-4, CEFIN Publishing House, Bucharest 2019;

[6] 0. Radu, GH. Săndulescu "Filtre Numerice Aplicații", 'Editura Tehnică', Bucharest, 1979

[7] http://imag.pub.ro/ro/cursuri/FourierStuff.pdf, accessed on 1.11.2021;

[8] involute_gear_profile.html, https://khkgears.net/new/gear knowledge/gear technical reference, accessed on 1.11.2021

[9] Technical Report ISO/TR 10064-1,"Cylindrical Gears - Code of inspections practice - Part 1: Inspection of corresponding flanks of gear teeth", 1992;

[10] Technical Report ISO/TR 10064-2,"Cylindrical Gears - Code of inspections practice - Part 2: Inspection related to radial composite deviations, runout, tooth thickness and backlash", 1996;

[11] Technical Report ISO/TR 10064-3,"Cylindrical Gears - Code of inspections practice - Part 3: Recommendations relative to gear blanks, shaft centre distance and parallelism of shafts", 1996;

[12] https://www.statista.com/statistics/1037208/ market-size-industrial-gearboxes-global/, accessed on 7.09.2021 